\title{
La integración multinacional latinoamericana y caribeña: un enfoque desde la prospectiva crítica y participativa
}

LUIS SUÄREZ SALAZAR

...la expresión integración multinacional debe entenderse como referente a una modalidad de agrupamiento de países soberanos, es decir, de Estados políticos reconocidos y aceptados internacionalmente como tales. Otro de sus significados implícitos es que se trata de una asociación voluntaria, consentida democráticamente en cada unidad miembro por cada sociedad involucrada. Por tanto, su semántica excluye la integración coercitiva en todas sus formas, desde la anexión hasta la unión impuesta por un poder hegemónico.

Gustavo Magariños

\section{Introducción}

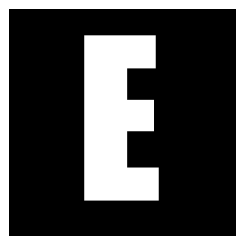

ste ensayo tiene el propósito de realizar una nueva aproximación ${ }^{1}$ y nuevas propuestas vinculadas a la actualidad y al futuro de los diferentes proyectos de integración multinacional latinoamericanos y caribeño que -según la definición del diplomático y profesor uruguayo Gustavo Magariños mencionada en el exordio- se están desarrollando en

\footnotetext{
* Doctor en Ciencias Sociológicas. Escritor Independiente, Profesor Auxiliar Adjunto de la Facultad de Filosofía e Historia de la Universidad de La Habana y Profesor Titular Adjunto del Instituto Superior de Relaciones Internacionales de La Habana, Cuba. 1 Los interesados en mis enfoques anteriores sobre este tema, pueden consultar, entre otos de mis textos: "Nuevo orden mundial, integración y derechos humanos en el Caribe: apuntes para una reconceptualización", en Globalización, integración
} 
la actualidad (Magariños, 2000). Geográficamente orientados de Norte a Sur y de Oeste a Este, estos son: el Sistema de Integración Centroamericano (SICA), la Comunidad del Caribe (CARICOM), la Comunidad Andina de Naciones (CAN) y el Mercado Común del Sur (MERCOSUR).

Como su título indica, ese enfoque se realizará desde los principales enunciados de la llamada "prospectiva crítica". Es decir, desde aquellos conceptos de la también llamada "futurología" que -a diferencia del determinismo y el voluntarismo que han caracterizado a la mayor parte de los cultores de esa disciplina- insisten en indicar que el futuro "es más construible que previsible" (José Mojica, 2000). En consecuencia, el porvenir se parece más a un juego de ajedrez o un campeonato de fútbol (donde los contendientes pugnan por triunfar), que a un guión de cine o a una pieza de teatro en las que el guionista, los actores y el director de la obra conocen el final de la trama.

Por tanto -como bien ha señalado el Director del Subnodo colombiano del Millennium Project del Consejo Americano de la Universidad de las Naciones Unidas, Francisco José Mojica- "el futuro" no es único, ni lineal. ${ }^{2}$ Al contrario, pueden vislumbrarse varios futuros y escenarios alternos. ${ }^{3}$ Ninguno de ellos está predeterminado por las tendencias del pasado o del presente; ya que, sin ignorar la importancia de su conocimiento científico, en última instancia, la consolidación, la modificación gradual o la ruptura radical de esas tendencias dependen de las acciones humanas. En particu-

\footnotetext{
y derechos humanos en el Caribe, ILSA, Santafé de Bogotá, Colombia; 1995. También, El siglo XXI: Posibilidades y desafíos para la Revolución cubana, Editorial de Ciencias Sociales, La Habana, 2000; América Latina y el Caribe: Medio siglo de crimen e impunidad (1948-1998), Zambon Iberoamericana/ Editorial José Martí, Zafarroa, España, y La Habana, 2001. Asimismo, Madre América: Un siglo de violencia y dolor (1898-1998), Editorial de Ciencias Sociales, La Habana, 2003.

2 Ídem.

3 En algunas aproximaciones teóricas-metodológicas a la Planeación Estratégica, los escenarios se clasifican en "escenarios probables", "escenarios alternos" y "escenarios deseados". Los primeros identifican y califican las tendencias de los procesos que se estudian. Los segundos refieren otras alternativas que podría deparar el porvenir, con independencia del grado de probabilidad que indiquen las tendencias dominantes en un momento determinado. Mientras que los terceros definen las mejores opciones para el cumplimiento de los objetivos de los "actores sociales" o de los "sujetos de pensamiento" y "sujetos de acción" implicados en ese proceso.
} 
lar, de "las acciones proactivas" del "hombre colectivo". ${ }^{4}$ Este, en ciertas corrientes del pensamiento sociológico, aparece identificado con las clases y las luchas de clases. ${ }^{5} \mathrm{Y}$, en otras, con los intereses y comportamientos de los "actores sociales" (Tourraine, 1984).

Por consiguiente, "la construcción del futuro no es un proceso neutral sino un campo de batalla (...) donde el sujeto de esta actividad que son los actores sociales pugnan por imponer su poder para defender sus intereses" ${ }^{6}$ Por ello: "La futurología supone un compromiso con el cambio y la acción que implica una voluntad de construir el futuro más que de aceptarlo simplemente".(Barbieri, 2000, p. 41-42). Lo anterior conlleva-cual planteó Max Weber- comprender "la política" como "el arte de luchar por lo imposible para obtener lo que sea posible en cada etapa". También implica potenciar lo que el desaparecido sacerdote jesuita Xabier Gorostiaga denominó la "prospectiva participativa". O sea, la construcción de futuros que reflejen la voluntad de las mayorías de los sujetos sociales (no sólo de "las elites" o "las vanguardias") de "organizar la esperanza" de que es "necesario y posible la edificación de una sociedad y un mundo mejor, fundado en una opción ética y en un compromiso por crear un futuro de ciudadanía digna para los excluidos y para los 'otros' desde la pasión y la compasión solidaria" (Gorostiaga, 2000, p. 35-49).

Comoquiera que sobre los mencionados proyectos subregionales de integración multinacional latinoamericanos y caribeño, además de las proyecciones externas $-y$, por tanto, la voluntad política- de los Estados y

\footnotetext{
4 En su ensayo ya mencionado Francisco José Mojica nos recuerda que comúnmente las actitudes humanas frente a los cambios en su entorno se definen con reactivas, preactivas y proactivas. Las primeras se reducen a encarar las situaciones críticas o conflictivas en el momento en que se presentan. Las segundas se limitan a prepararse para los cambios, bajo el supuesto de que estos no dependen de su voluntad. Y la tercera es la que vincula la acción humana a una actividad conscientemente dirigida a la construcción del futuro.

5 Ernesto Che Guevara: «La planificación socialista, su significado», en Obras 1957-1967, Casa de las Américas, Tomo II, La Habana, 1970, pp. 319-331. A partir de los enunciados de la sociología marxista, en ese ensayo su autor afirma: “...nunca se puede desligar el análisis económico del hecho histórico de la lucha de clases, ni del hombre, 'expresión viviente' de esas luchas".
} 
gobiernos implicados, ${ }^{7}$ actúan, para bien o para mal, los diversos procesos económicos, sociales, políticos, militares e ideológicos-culturales relacionados con la llamada "globalización", en el primer acápite presentaré, de manera sintética, algunas de mis aproximaciones teóricas a ese complejo, caótico, multidimensional y contradictorio fenómeno nacional, pannacional y transnacional. ${ }^{8}$

A su vez, en el segundo acápite, colocaré la mirada en los relativamente exitosos esfuerzos que, desde 1989 (fecha de la brutal ocupación militar norteamericana de Panamá), han venido desarrollando sucesivos gobiernos de Estados Unidos - en consuno con los sectores dominantes en la mayor parte de los países de América Latina y el Caribe, al igual que en Canadá - con vistas a reformular su sistema de dominación y, como parte de ese proceso multidimensional, a institucionalizar lo que, desde hace varios años, he venido denominando "un nuevo orden panamericano" o lo que, en la misma tesitura, John Saxe-Fernández llamó: "la regionalización neomonroista del hemisferio occidental" (Saxe-Fernández, 1996).

Como he indicado en otras ocasiones, uno (sólo uno) de los pilares de esa proyección imperialista ha sido y es la negociación del Acuerdo de Libre Comercio para las Américas (ALCA) que se viene negociando desde la Segunda Cumbre de las Américas efectuada en Santiago de Chile en

\footnotetext{
6 Francisco José Mojica: Ob. cit.

7 Como en otros de mis textos, utilizó el concepto "proyección externa" para connotar acontecimientos y definiciones que, aunque strictu sensu forman parte del orden político y jurídico interno o de la política económica, ecológica o cultural de un Estado-nación, contribuyen (o no) a materializar su política exterior y, por tanto, sus plurales interrelaciones con el mundo. 8 En su ensayo "Procesos de construcción de identidades transnacionales en América Latina en tiempos de globalización" (Teoría y práctica política de construcción de identidades y diferencias en América Latina y el Caribe, UNESCO-Editorial Nueva Sociedad, Caracas, 1994) Daniel Mato diferencia los procesos transnacionales, de los pannacionales. Estas últimos tienen que ver con los acuerdos intergubernamentales; mientras que los primeros aluden a los procesos donde participan otros actores sociales. Entre uno y otro proceso pueden existir coincidencias o francas divergencias; particularmente entre las autoridades de los Estados y los actores sociales que, por diferentes razones, desconocen sus fronteras y su soberanía nacional; cual es el caso típico de las Empresas Transnacionales y Multinacionales que actúan en lo que Inmanuel Wallerstein denomina "la economía-mundo".
} 
1998. En caso de protocolizarse, total o parcialmente, tal acuerdo -jalonado por otros componentes de la estrategia estadounidense que menciono en el ensayo- objetivamente propiciará lo que Gustavo Magariños Ilama "la integración coercitiva" y, por tanto, subordinada y dependiente de América Latina y el Caribe a las bicentenarias aspiraciones geopolíticas y geoeconómicas, así como a las actuales necesidades estratégicas de los grupos dominantes en Estados Unidos.

Por ende, como se verá en el tercer acápite, la evolución de la política exterior, económica y de seguridad del establishment de Estados Unidos, su aceptación (o rechazo) por parte de los gobiernos del hemisferio occidental, ha tenido (y seguramente tendrá) un impacto significativo en la definición de las disyuntivas que actualmente tienen que encarar todos los proyectos de integración multinacional -tanto de concertación política, como de "integración económica"-que se desenvuelven entre los países situados el sur del río Bravo y de la península de La Florida.

Finalmente, a modo de conclusión, y siguiendo mis reflexiones más recientes (Suárez Salazar, 2004), presentaré algunos criterios que pudieran servir de base al impulso de lo que he llamado "un nuevo paradigma para la integración multinacional latinoamericana y caribeña"; entendiendo esa integración -tal cual propone la denominada Alternativa Bolivariana para las Américas (ALBA) impulsada por los presidentes de la República Bolivariana de Venezuela y de Cuba, Hugo Chávez y Fidel Castro, ${ }^{9}$ respectivamente-como un proceso multifacético (y, por tanto, no sólo económico) que, poco a poco, aproxime a todas las naciones (incluidas las originarias) y a todos los pueblos de esa región a la realización de la utopía bolivariana y martiana. En particular, a los irrealizados anhelos de esos Próceres con

9 Declaración Conjunto y Acuerdo entre el Presidente de la República Bolivariana de Venezuela y el Presidente del Consejo de Estado de Cuba, para la aplicación de la Alternativa Bolivariana para las Américas, en "Chávez volvió gigante", Granma, Suplemento Especial, La Habana, Cuba, diciembre del 2004. 
relación a que todos los Estados-nacionales de América Latina y el Caribe luego de concluir su descolonización y de forjar la unidad entre sí - puedan actuar como un "factor de equilibrio" en la edificación de un orden mundial alternativo al que en la actualidad están impulsando las principales potencias imperialistas del planeta; y, en especial, los grupos dominantes en Estados Unidos.

La globalización: ¿última fase de la última fase?

En los últimos años y especialmente después de la aparición en el año 2002 del libro Imperio de Michael Hardt y Antonio Negri, ${ }^{10}$ se ha venido desarrollando una intensa polémica alrededor de la validez de los criterios de esos autores y, vinculado a ello, a la definición de los conceptos que usualmente se emplean para definir "la globalización". ${ }^{11}$ Con vistas a participar en ese debate, a comienzos del año 2003, actualicé, para su publicación, un artículo inicialmente titulado "La globalización: ¿Fase superior y última del imperialismo?"(Suárez Salazar, 1999). Esa actualización apareció en la revista Temas, de La Habana, Cuba, bajo el título "La globalización: ¿última fase de la última fase?"(Suárez Salazar, 2003, p. 139-148).

No es mi propósito reproducir ahora todos los elementos y datos empíricos que aparecen en esos artículos y en la más reciente actualización (aún inédita) que le he realizado. ${ }^{12}$ Sin embargo, como preámbulo a mi aproximación a las disyuntivas de los actuales procesos de integración

\footnotetext{
10 Michael Hardt, y Antonio Negri: Imperio, Piados, Buenos Aires, 2002.

11 Además de los diversos artículos que aparecen en la revista Temas, de La Habana, Cuba, a la que haré referencia después, los interesados pueden consultar, entre otros textos, Atilio Borón: Imperio \& Imperialismo, Consejo Latinoamericano de Ciencias Sociales, Buenos Aires, 2002.

12 Luis Suárez Salazar: "La globalización: una lectura desde los marxismos", ponencia presentada al Seminario Internacional Marx Vive: Resistencias y alternativas en América Latina, Universidad Nacional de Colombia, Bogotá, 3 al 5 de noviembre del 2004.
} 
multinacional que se desenvuelven en América Latina y el Caribe, me parece necesario reiterar que, en mi concepto (compartido por otros autores latinoamericanos, europeos y estadounidenses), ${ }^{13}$ no podemos comprender las esencias de "la globalización" y de los procesos de "regionalización" e "integración" que, con fines ofensivos o defensivos, ${ }^{14}$ se han venido desplegando en los últimos tres lustros sin apropiarnos de manera crítica, actualizada, antidogmática y creadora de los criterios de Carlos Marx acerca de la internacionalización del capital y de sus sujetos sociales (la burguesía y el proletariado) (Marx, 1962). Asimismo, de la manera en que se expresa ese continuo proceso en la fase del capitalismo que Vladimir Ilich Lenin indistintamente Ilamó: "el capitalismo monopolista", "el capitalismo monopolista de Estado" o, simplemente, el "fenómeno imperialista" (Lenin, 1976, p. 372-500).

Desde mi punto de vista, lo antes dicho es así porque en los actuales procesos de la que también he Ilamado "la globalización asimétrica y excluyente" (Suárez Salazar, ed. cit) (y que otros autores han denominado "la globalización liberal" o "el imperialismo global") (Cornil, 2003, p. 1427) se pueden identificar, incluso de una manera más nítida que a comienzos del siglo XX, lo que Lenin -para burlar la censura zarista- definió, en 1917, como los "cinco rasgos económicos" de la "fase más reciente del

\footnotetext{
13 Entre los primeros, Atilio Borón y Narciso Isa Conde. Entre los segundos, Estefan Engel. Y, entre los terceros, James Petras y William Robinson. Los interesados en conocer las reflexiones de esos autores pueden consultar las reflexiones del primero en el libro ya mencionado. A su vez, es el segundo es autor de Los Halcones atacan. Estrategia E.U. en el siglo XXI y alternativa revolucionaria (Editora Tropical, República Dominicana, 2002). De Estefan Engels puede consultarse: Crepúsculo de los Dioses sobre el "nuevo orden mundial", Editorial Neuer Weg, República Federal Alemana, 2004. Finalmente, de la voluminosa obra de Petras pueden verse: "Imperialismo, Militarismo y las Contradicciones del Imperio", ponencia a la Conferencia Internacional "Martí y el equilibrio del mundo", efectuada en La Habana, Cuba, entre el 27 y el 29 de enero del 2003. Mientras que Robinson es autor de: "El capitalismo global y la hegemonía capitalista transnacional: Apuntes teóricos y evidencias empíricas", en Cuadernos de Nuestra América, No. 31 y 32, La Habana, enero-junio y julio-diciembre del 2003. 14 Como ya planteé, en el empleo operacional de estos conceptos me adscribo a las definiciones de Gustavo Magariños. Para este, como ya vimos, existen diferentes modalidades de integración interestatal; pero todas ellas se diferencian de los procesos de regionalización; entendiendo por estos aquellos destinados a crear interdependencias o dependencias entre unidades regionales carentes de autonomía propia desde el punto de vista internacional. Es decir, entre regiones que forman parte de diferentes Estados-nacionales.
} 
capitalismo". ${ }^{15}$ Es decir: la creciente concentración y centralización de la producción, los capitales y los conocimientos, así como el consiguiente surgimiento de diversos monopolios (trusts, cartels y alianzas estratégicas corporativas) que juegan un papel cada vez más decisivo en la vida política, social y económica de la mayor parte de los países del mundo. Asimismo, la galopante fusión del capital bancario con el capital industrial y de estos con los centros productores de nuevos conocimientos científicos-técnicos para dar origen a lo que -en los textos antes referidos y ampliando lo planteado por Lenin- Ilamé: "la oligarquía financiera y tecnotrónica transnacionalizada." O a lo que, de manera paralela, William Robinson ha denominado: "la clase capitalista transnacional". ${ }^{16}$

Igualmente, y también siguiendo lo planteado por Lenin, en la actualidad pueden identificarse de manera empírica: la acelerada importancia que, en la fase imperialista, tiene en los flujos económicos internacionales la exportación de capitales con relación a la exportación de mercancías; el carácter cada vez más especulativo y parasitario del capitalismo; y la formación de poderosas agrupaciones monopólicas u oligopólicas internacionales (las Ilamadas: Empresas o Corporaciones Transnacionales y Multinacionales) que, unidas a los Estados y gobiernos de las principales potencias imperialistas, siguen luchando entre sí por repartirse el mundo. ${ }^{17}$

A pesar de los acuerdos y coincidencias existentes en el manejo de diversos asuntos internacionales entre las potencias capitalistas que integran la denominada "tríada del poder mundial" (Estados Unidos, Japón y la Unión Europea) (Ohmae, 1991), en la actualidad también pueden

\footnotetext{
15 Como indico en uno de mis artículos ya mencionados, el titulo original de la obra de Lenin ya referenciada fue: El imperialismo, fase más reciente del capitalismo. En razón de un desliz en la traducción del ruso al español, es que esa obra ha sido popularizada con el titulo: El imperialismo, fase superior y última del capitalismo.

16 William Robinson: ob. cit.

17 Vladimir Ilich Lenin: ob. cit.
} 
visualizarse lo que Lenin Ilamó las "contradicciones ínter imperialistas". ${ }^{18}$ Aunque es cierto que -a diferencia de lo que ocurrió en el siglo XX (particularmente antes del fin de la Segunda Guerra Mundial) y como consecuencia del enorme potencial destructivo y disuasivo de los armamentos nucleares- esas contradicciones no han conducido a nuevas guerras mundiales, nada indica que, en el futuro previsible, no se provocarán enconados conflictos económicos, políticos, ideológico-culturales y hasta político-militares (sobre todo en los escenarios del todavía llamado Tercer Mundo y de los países en "transición" del socialismo al capitalismo de Europa central y oriental) entre las potencias imperialistas antes mencionadas o, eventualmente, de éstas con Rusia y la República Popular China (RPCh). Esta última, considerada como "una potencia emergente" llamada a integrar, con todo derecho, lo que algunos autores definen como "la pentarquía" o "el sexágono" del "nuevo orden mundial". ${ }^{19}$

Entre otros datos empíricos (como las discrepancias de la Casa Blanca con los gobiernos de algunas potencias euroasiáticos en torno a la guerra de Irak (Roque Valdés, 2003, p. 58-75), o con relación a sus correspondientes políticas hacia Asia, África, Latinoamérica y el Caribe, incluida Cuba), así lo preanuncian las pugnas nipo-norteamericanas, intraeuropeas (Inglaterra frente a Alemania y Francia), intraasiáticas (China vs. Japón y Estados Unidos) o euro-norteamericanas por el control de los mercados mundiales, regionales y nacionales; por utilizar a su favor todos los espacios del planeta e incluso del cosmos o por garantizar o ampliar sus tradicionales "esferas de influencia". Aunque no son las únicas, una expresión típica de estas últimas contradicciones son los conflictos latentes entre Rusia, los Estados Unidos

\footnotetext{
18 Vladimir Ilich Lenin: ob. cit.

19 Entre los que hablan de "la pentarquía del poder mundial" merece mencionarse el artículo de Xue Moufang, titulado "¿Cuatro potencias y una superpotencia" que apareció en Beijin Informa del 26 de septiembre de 1995. Los que mencionan "el sexágono del poder mundial", incluyen -junto a Japón, la UE, los Estados Unidos, Rusia y la RPCh-a la India. Por su población, potencial económico y dominio de los armamentos nucleares, esta última es considerada por ciertos medios de Estados Unidos como "otra potencia democrática" del mundo.
} 
y la Unión Europea (UE) respecto a la ampliación hacia el Este de las fronteras de esta última agrupación multinacional, al igual que acerca de los límites y misiones de la Organización del Atlántico Norte (OTAN) fundada en los albores de la llamada "guerra fría".

Lo antes dicho - al igual que los continuos afanes hegemónicos de los círculos de poder estadounidenses (fortalecidos después del "golpe de Estado jurídico" de diciembre del 2000 protagonizado por los sectores más reaccionarios del Partido Republicano (Montoya, 2003), y de la reelección, en noviembre del 2004, de George W. Bush)- contribuye a explicar la perdurable militarización de algunas economías capitalistas centrales y, en primer lugar, de la economía estadounidense. Así lo demuestra, entre otras cosas, el salto sideral (cerca de 400 mil millones de dólares anuales) que con el pretexto de la "guerra contra el terrorismo de alcance global" y bajo los agresivos enunciados de la Estrategia de Seguridad Nacional dada a conocer en septiembre del 2002 por el actual mandatario estadounidense $-{ }^{20}$ ha registrado el presupuesto militar de ese país en los últimos cuatros años.

Según diversos especialitas, en el futuro próximo, esa y otras decisiones posteriores de la principal potencia imperialista del mundo impulsará la carrera armamentista entre las restantes potencias con derecho al veto en el Consejo de Seguridad de la ONU (el Reino Unido, Francia, la Federación Rusa y la RPCh). Mucho más porque resulta cada vez más claro que, mediante el incremento de su indiscutible poderío militar, los grupos dominantes en los Estados Unidos quieren compensar sus debilidades internas (caída de la productividad del trabajo, perdida de competitividad de sus exportaciones, abultados déficit en su comercio exterior y en su balanza de pagos, incremento de sus deudas interna y externa) (Wallerstein, 2003,

\footnotetext{
20 Luis Suárez Salazar: “La nueva estrategia de seguridad nacional de los Estados Unidos: implicaciones para la paz, el Derecho Internacional Público contemporáneo y el 'nuevo orden panamericano'", en Nueva Democracia, Edición Especial, México, Otoño del 2003, pp. 79-91.
} 
p. 99-102) para lidiar en algunos campos de lo que Joseph Ney Jr. llamó “el tablero de ajedrez tridimensional (bélico, económico y transnacional) que caracteriza (y caracterizará) el nuevo orden mundial" (Nye Jr., 1998).

Obviamente, con lo anterior no quiero decir que lo que Benjamín Coriat denominó la "exacerbada competencia crucial y multidimensional" existente entre diversas corporaciones transnacionales (Coriat, 1994), y entre las potencias integrantes de la tríada o de la pentarquía del poder mundial termine inevitablemente en una nueva guerra mundial. ${ }^{21}$ Sólo quiero acentuar que, a diferencia de otros autores y sin negar el peso específico del llamado "unipolarismo estadounidense" (Dieterich, 1995), considero que la pugna ínter imperialista continúa y continuará presente en el funcionamiento del sistema internacional. Sobre todo por las implicaciones negativas que tienen las acciones de los grupos conservadores y neoconservadores que actualmente controlan las diferentes instancias de poder en Estados Unidos sobre los intereses geopolíticos o geoeconómicos de otras potencias euroasiáticas. En particular, para Alemania, Francia, la RPCh y Rusia.

También por la importancia que continúa teniendo para los principales consorcios transnacionales y multinacionales la preservación y ampliación de sus mercados en diversos países o zonas del "capitalismo central", al igual que el empleo de las fuentes de materias primas estratégicas, de los combustibles fósiles, de los recursos biogenéticos, de la "mano de obra barata" e, incluso, de las principales fuentes de agua potable existentes en el planeta. Igualmente, el control por parte de sus correspondientes Estados-nacionales de aquellos espacios geográficos (terrestres, marítimos y aéreos) indispensables para el comercio internacional, así como para el

\footnotetext{
21 Quiero resaltar que Lenin nunca dijo que, en todos los casos, la competencia ínter imperialista llegaría a esos extremos. Por el contrario, afirmó y demostró que la mayor parte de las veces ésta se desarrollaba por medios pacíficos o mediante movimientos pendulares entre las vías pacíficas, las violentas y las bélicas.
} 
desplazamiento fuera de sus fronteras de sus desechos peligrosos y de sus fuerzas militares. Así lo confirma, entre otros ejemplos, el persistente propósito del establishment de la política exterior y de seguridad de Estados Unidos de mantener su control sobre el istmo centroamericano, sobre el Golfo de México, sobre el Mar Caribe y sobre el norte de América del Sur; en especial sobre las vías acuáticas y terrestres consideradas como insustituibles para garantizar el rápido tránsito entre los océanos Atlántico y Pacífico.

\section{Hacia un "nuevo orden panamericano"}

Lo antes dicho me coloca en la importancia que - desde mi punto de vista - tiene la que Gustavo Magariños Ilama "la integración coercitiva" de América Latina y el Caribe para los grupos dominantes en Estados Unidos. Aunque algunos especialistas consideran (y no sin razón) que, sobre todo, después del inicio de las guerras "contra el terrorismo" en Afganistán y en Irak, las relaciones con las naciones del hemisferio occidental han perdido relevancia para la Casa Blanca, ${ }^{22}$ soy del criterio que, en la persistente y bicentenaria percepción geopolítica y geoeconómica del establishment de la política exterior, de defensa y de seguridad de esa potencia imperialista, las naciones situadas al sur del río Bravo y de la península de la Florida siguen siendo visualizadas - en las palabras de los redactores de los Documentos de Santa Fe — como "el escudo y la espada para la proyección del poder global de los Estados Unidos". ${ }^{23}$

\footnotetext{
22 La percepción de que América Latina y el Caribe han perdido importancia para la Casa Blanca se ha acentuado como consecuencia de la ausencia de referencias a la región en el más reciente debate electoral estadounidense. Sin embargo, como se verá el texto, esa ausencia puede explicarse, más que por su presunto desinterés, por la existencia de un consenso vertebral entre los grupos dominantes en los Estados Unidos con relación a los principales componentes de su estrategia hacia la región. 23 Comité de Santa Fe: “Las relaciones interamericanas: escudo de la seguridad del Nuevo Mundo y espada de la proyección del poder global de Estados Unidos, en Documentos, No. 9, Centro de Estudios sobre América, La Habana, 1981.
} 
Cual he indicado en otras ocasiones, ${ }^{24}$ sin negar la existencia de ciertos matices diferenciales entre las políticas hemisféricas de los dos partidos preponderantes en el sistema político estadounidense, así lo demuestran, además de sus comportamientos históricos, las consistentes y bipartidistas estrategias desplegadas, desde diciembre de 1989 (fecha de la invasión militar norteamericana a Panamá y del inicio del "fin de la guerra fría") hasta la actualidad, por las tres últimas administraciones demócratas y republicanas que han ocupado la Casa Blanca (las presididas por George H. Bush, por William Clinton y por George W. Bush) con vistas a reformular, en consuno con las clases dominantes en diferentes países del hemisferio occidental (incluido Canadá), su sistema de dominación sobre América Latina y el Caribe y - como parte de ese multidimensional empeño - a institucionalizar lo que he denominado "un nuevo orden panamericano". Esos afanes se ha expresado en diversas dimensiones interrelacionadas entre sí de sus correspondientes proyecciones externas. ${ }^{25}$ Sin orden de prelación, entre esas dimensiones, quiero destacar las siguientes:

1. La institucionalización de las Cumbres de las Américas. La novedosa importancia que tienen para el gobierno de Estados Unidos esas sistemáticas reuniones presidenciales queda en evidencia cuando observamos (además de su actual periodicidad) que, en los 190 años de relaciones interamericanas precedentes a la convocatoria de la primera Cumbre de las Américas (Miami, 1994), ${ }^{26}$ sólo se habían realizado dos reuniones de ese carácter: la efectuada en

\footnotetext{
24 Luis Suárez Salazar: América Latina y el Caribe: Medio siglo de crimen e impunidad (1948-1998) y Madre América: Un siglo de violencia y dolor (1898-1998), ed. cit.

25 Utilizó el concepto "proyección externa" para incluir en el análisis lo que Abraham Lowenthal ha denominado "los problemas intermésticos" que afectan a las relaciones entre Estados Unidos y América Latina y el Caribe; tales como el problema de las drogas y otros delitos conexos, al igual que los diferentes componentes de la agenda migratoria.

26 Tomo como fecha del inicio de las relaciones interestatales interamericanas, la independencia de Haití, del 1 ro de enero de 1804. Hasta ese momento e incluso en las dos décadas posteriores, los interlocutores de la estrategia de Estados Unidos hacia el llamado Nuevo Mundo eran las principales potencias euroasiáticas (España, Inglaterra, Francia, Holanda, Dinamarca y Rusia) con intereses en el posteriormente denominado Hemisferio Occidental.
} 
Panamá, en 1956, durante la presidencia de Dwight Eisenhower (1953-1961); y la convocada, en 1967, por Lyndon B. Johnson (1963-1969) en Punta del Este, Uruguay. Por otra parte, en ninguna de esas citas habían participado los jefes de Estado y gobierno de 34 (con la exclusión del de Cuba) de los 35 países del hemisferio occidental. Además, ninguna de ellas había definido -como se hizo en la Segunda Cumbre de las Américas (Santiago de Chile, 1998)mecanismos de seguimiento de sus acuerdos y resoluciones. Tampoco habían sido acompañadas por continuas reuniones políticas y técnicas de los Ministros, Secretarios y otros altos funcionarios vinculados prácticamente a todas las esferas de la actividad gubernamental, incluidas la seguridad y la defensa, de los países participantes en esas cumbres (Ruíz Blanco, 2003, p. 113-132).

2. Como parte de esas y otras reuniones, se han venido protocolizando diversas reformas a la Carta de la Organización de Estados Americanos (OEA), al igual que múltiples Convenciones Interamericanas (como las de la asistencia mutua en Material Penal, contra la corrupción, contra la fabricación y el tráfico ilícito de armas de fuego, municiones, explosivos y otros materiales relacionados, así como contra el llamado "narcoterrorismo") que, de una u otra forma, comprometen la cooperación militar, policial y de inteligencia de los 34 países miembros de la OEA. Para tratar de consolidar esos acuerdos se efectuó en México (27 y 28 de octubre del 2003) una Conferencia Especial de todos esos gobiernos con vistas a tratar de definir sus nociones comunes acerca de los denominados "nuevos enemigos de la seguridad interamericana". Aunque -cual se demostró en la más reciente Cumbre de Ministros de Defensa efectuada en Ecuador a comienzos del 2005- subsisten discrepancias (fundamentalmente vinculadas a la definición de la llamada 
"seguridad multidimensional" propugnada por América Latina y el Caribe, así como respecto al papel y la subordinación de la Junta Interamericana y del Colegio Interamericano de Defensa), todo parece indicar que la intención de Estados Unidos es obtener la aprobación de nuevos compromisos en los terrenos de la seguridad y la defensa entre todos los Estados que actualmente integran la OEA; incluso aquellos (como Canadá y los Estados caribeños) que no son signatarios o que (como el es el caso de México) han denunciado el ya obsoleto y desprestigiado Tratado Interamericano de Asistencia Reciproca (TIAR) firmado por 20 gobierno del hemisferio occidental en 1947 (Bermúdez Torres, 2003, p. 81-112).

3. Con independencia de los resultados de las deliberaciones antes aludidas, desde la segunda mitad de la última década del siglo XX, el establishment de la política exterior, de defensa y seguridad de Estados Unidos progresivamente ha venido redefiniendo las misiones, estructuras y dislocación de sus fuerzas armadas (y de seguridad) en ese hemisferio; en particular las del Comando Sur (máximo responsable de las acciones militares y de seguridad que se desplieguen en Centro y Suramérica, así como en la mayor parte de los territorios del Ilamado "archipiélago de las Antillas"), ${ }^{27}$ y del recién constituido Comando Norte, encargado de "la defensa" de Canadá, Estados Unidos, México, al igual que de Cuba y Puerto Rico. Lo anterior ha sido acompañado por la suscripción de diversos acuerdos bilaterales de seguridad y defensa entre Estados Unidos y varios gobiernos latinoamericanos y caribeños, así como por el despliegue de nuevas "facilidades" militares (entre ellas, los ahora

\footnotetext{
27 Humberto García Muñiz y Jorge Rodríguez Beruff: Fronteras en conflicto: Guerra contra las drogas, militarización y democracia en el Caribe, Puerto Rico y Vieques, Red Caribeña de Geopolitica, Seguridad Regional y Relaciones Internacionales, San Juan, Puerto Rico, 1999.
} 
llamados Centros Operativos de Avanzada: FOL por sus siglas en inglés) en diferentes países del hemisferio occidental, cuales son: El Salvador, Honduras, Colombia, Ecuador y Perú. Estas se suman a los poderosos radares ROTHR ubicados en el sur de Estados Unidos, a las bases militares "tradicionales" que perduran en Cuba y en el colonizado archipiélago de Puerto Rico, así como a las FOL instaladas -con el pretexto de la lucha contra el "narcoterrorismo" y con la anuencia de la monarquía constitucional holandesa - en Aruba y Curazao. ${ }^{28}$ Objetivamente, todo ello - junto a las maniobras militares que continúan desarrollándose (entre ellas, las bautizadas por el Pentágono con el apelativo Nuevos Horizontes) en diferentes países latinoamericanos (Argentina, Guatemala, Panamá, República Dominicana), a la creciente presencia de los órganos de seguridad y de la inteligencia estadounidenses en la llamada Zona de la Triple Frontera (Argentina, Brasil y Paraguay) y a la ocupación militar de Haití (29 de febrero del 2004) - crea un fortalecido dispositivo de defensa y seguridad que tiende a subordinar a diversos países latinoamericanos y caribeños a la "nueva" Estrategia de Seguridad imperial de los Estados Unidos. ${ }^{29}$ Además, la impunidad con que actúan sus fuerzas militares y de seguridad se ha venido protocolizando en los mal Ilamados Acuerdos Bilaterales de Inmunidad (BIA, por sus siglas en inglés) dirigidos a lograr, de manera compulsiva, que los crímenes (incluidos los de lesa humanidad) que perpetren los funcionarios militares y civiles estadounidenses queden fuera del alcance de la Corte Penal Internacional, así como de los tribunales de los Estados-nacionales donde actúan (García Rivera, 2003).

\footnotetext{
28 Theo Ronchen: La lucha contra las drogas y la proyección militar de Estados Unidos: Centros Operativos de Avanzada en América Latina y el Caribe, ABYA YALA/ Transnational Institute, Quito, Ecuador, 2004.

29 Luis Suárez Salazar: "La nueva estrategia de seguridad nacional de los Estados Unidos: ...", ed. cit.
} 
4. A lo anterior se une "la modernización" del Sistema Interamericano; en especial de la OEA (Faya, 1994). Aunque desde su fundación, en 1948, esa institución siempre ha sido visualizada por el Departamento de Estado como un complemento utilitario (y, por tanto, selectivo) de su política hacia América Latina y el Caribe, no hay dudas que, desde la Asamblea General de la OEA efectuada en Santiago de Chile en 1991, el gobierno estadounidense (en consuno con la mayor parte de los Estados y gobiernos actualmente integrantes de la misma) ha venido impulsando una sistemática modernización de todos los órganos y comisiones se ese organismo hemisférico, así como una constante ampliación de sus ámbitos de competencia; entre ellos, la seguridad (en 1995, la OEA creó un Comité de Seguridad Hemisférica) y otros asuntos (como los procesos electorales) que previamente estaban nítidamente colocados en el campo de la soberanía y la política interna de sus estados miembros (Herz, 2003). Vinculado con esto último, desde el Compromiso de Santiago de Chile de 1991 y del Ilamado Protocolo de Washington de 1992 (entró en vigor en 1997), la OEA reforzó su compromiso con la llamada "democracia representativa". Con independencia de los constantemente violados enunciados al respecto que ya existían en la Carta de la OEA, por primera vez en la historia de las relaciones interamericanas, esa restringida noción de la democracia adquirió carácter vinculante $-y$, por tanto, condicionante del orden político-jurídico interno de los Estados miembros- en la Tercera Cumbre de las Américas (Québec, Canadá, 2001). Pero, sobre todo, luego de la aprobación unánime, el 10 de septiembre del propio año, en la Asamblea General de la OEA efectuada en Lima, Perú, de la llamada Carta Democrática Interamericana. No obstante algunas contradicciones que subsisten en su letra (las men- 
ciones a la "democracia participativa" incluidas por la presión del gobierno de la República Bolivariana de Venezuela, al igual que respecto a la interpretación de los incisos relativos a las "intervenciones colectivas" que podrá emprender el organismo regional), como resultado de esa carta, la OEA ensanchó sus capacidades para emprender "intervenciones democráticas colectivas" en los asuntos internos de sus actuales Estados miembros, aún cuando en el futuro algunos de estos sean separados de esa organización. Además, de jure, quedó establecida una "cláusula democrática" que condiciona la participación de todos los Estados del hemisferio occidental en el llamado "proceso de la Cumbre de las Américas". Se anuló así el llamado "principio del pluralismo político-ideológico" que había sido aceptado por ese organismo regional desde la segunda mitad de la década de 1970 y, en particular, luego del Protocolo de Reforma al TIAR aprobado en 1975.

5. El abandono de ese principio se vincula a los avances que ha venido obteniendo Estados Unidos en la definición de la agenda política e ideológico-cultural de la mayor parte de los países del hemisferio occidental. Gracias a esos avances, la llamada "diplomacia pública" (la propaganda facturada por las agencias especializadas, incluida la CIA, del gobierno o del Congreso estadounidense, como la National Endowment for Democracy), sus grandes medios de comunicación masiva y sus poderosas industrias culturales han logrado nuevos canales -como el empleo de la INTERNET y de otros circuitos de la "cultura a domicilio" (la TV por cable), así como de la "cultura situada" (en particular los cines)- para difundir, al menos, entre las elites y las "clases medias" latinoamericanas y caribeñas diversos mensajes y un "imaginario transnacional" facturado alrededor de las supuestas superioridades del "modo de vida" y del 
sistema político norteamericano (García Canclini, 1996). Como bien se ha indicado, ese "imaginario trasnacional" made in USA atenta contra las identidades culturales territoriales y nacionales previamente existentes en América Latina y el Caribe e incide negativamente en el continúo proceso de construcción de las identidades y diferencias con Estados Unidos (y con otras partes del "mundo desarrollado") que requiere Nuestra América para edificar las nuevas nociones civilizatorias necesarias para avanzar en sus esquivos procesos de integración multinacional (Columbres, 2001). En especial porque, contra toda evidencia empírica, gracias a la acción de la también llamada "propaganda política exterior" estadounidense (reproducida todos los días por los principales medios de difusión masiva latinoamericanos y caribeños) se ha venido difundiendo lo que Ignacio Ramonet ha llamado "el pensamiento único", ${ }^{30}$ así como la supuesta existencia de una "interdependencia simétrica" y de "intereses compartidos" entre las "dos Américas". Es decir, entre Estados Unidos, Canadá y América Latina y el Caribe.

6. Objetivamente, la difusión del "imaginario transnacional" y la ampliación de los canales para trasmitirlo antes mencionados se multiplicarán en el caso de que finalmente sea aprobado, total o parcialmente, el llamado Tratado de Libre Comercio para las Américas (ALCA); en tanto la "libre" circulación de mercancías, servicios y capitales previstos en ese acuerdo también incluyen los bienes y servicios culturales. Sobre todo si, como pretende y en cierta medida ya ha venido logrando el gobierno de Estados Unidos en los tratados de libre comercio bilaterales (como los recientemente signados con Chile y República Dominicana) o plurilaterales (como el Tratado de 
Libre Comercio con Centroamérica), se adoptan los llamados acuerdos "OMC plus". Es decir, las normativas vinculadas a la propiedad intelectual, a los derechos de autor, a las patentes, secretos comerciales y marcas (los denominados "derechos de propiedad intelectual vinculados al comercio") y a otros temas "comerciales" (como algunas de las draconianas normativas incluidas en el hasta ahora frustrado Acuerdo Multilateral de Inversiones elaborado en la década pasada por la Organización para la Cooperación y el Desarrollo) que aún no han sido aprobadas por la Organización Mundial del Comercio (OMC). Pero - como bien se ha dicho- aún en el caso de que lo anterior no ocurriera, ya sea por la oposición del Congreso de Estados Unidos a los tratados antes mencionados o por el rechazo de algunos gobiernos latinoamericanos y caribeños a ciertas partes del texto original del ALCA, y que, al final, sólo se apruebe el denominado "ALCA light" (Serbin, 2003, p. 86-100), en razón de la sola aceptación de las nociones acerca del "libre comercio" y de la presunta "reciprocidad" entre Estados con tal asimetría de poderes y recursos, los Estados y gobiernos de América Latina y el Caribe (incluso los de mayor desarrollo relativo) seguramente perderán sus ya reducidas capacidades para definir su propia agenda de desarrollo, incluidas sus relaciones con el capital transnacional de origen estadounidense, sus políticas comercial, financiera, monetaria, industrial, ecológica, social y cultural (Benjamín y Tavares Ribeiro, 2004, p. 26-32).

Sobre todo porque al ALCA (o a algunas de sus modalidades hemisféricas, plurilaterales o bilaterales) se llegará después del terrible impacto desintegrador que ha tenido sobre la mayor parte de los países de la región (incluso sobre los llamados a liderar su integración multinacional, como Argentina, Brasil y México) los Programas de Ajustes Estructural (PAE) impulsados por el Departamento del Tesoro de Estados Unidos, por el Fondo Monetario Internacional y por el Banco Mundial (Stiglitz, 2002). 
Como demuestran todas las evidencias empíricas disponibles, esos programas de corte neoliberal en lo económico y neoconservador en lo político junto a su pareja: "la deuda eterna" - han limitado la soberanía de los Estados y gobiernos que lo han aplicado; ensanchado "la brecha social" previamente existente; ampliado los desastres ecológicos y ambientales en las zonas rurales y en muchas ciudades; y profundizado la "crisis dentro de la democracia" que viven los restringidos sistemas políticos liberales-burgueses (las también llamadas "poliarquías") instaurados en la mayor parte de los países latinoamericanos y caribeños. ${ }^{31}$ También han condicionado los "modelos de desarrollo hacia afuera" aplicados por los gobiernos de esa región; "abierto" unilateralmente las economías "nacionales" a los bienes, servicios y capitales (incluso los especulativos) provenientes del exterior; privatizado y/o desnacionalizado importantes riquezas; así como fortalecido la multiforme dependencia estructural y funcional de la mayor parte de los países formalmente independientes del hemisferio occidental (incluido Canadá) hacia las principales potencias imperialistas; en primer lugar hacia Estados Unidos (Santos, 2002).

\section{Las disyuntivas de los actuales esquemas de integración multinacional latinoamericanos y caribeños}

Todo lo antes dicho, junto a la ostensible falta de voluntad política de la mayor parte de los Estados y gobiernos de América Latina y el Caribe, así como a los mezquinos intereses de las clases dominantes en esa región,

\footnotetext{
31 Guillermo O’Donell: “llusiones sobre la consolidación”, en Nueva Sociedad, No. 144, Caracas, julio-agosto de 1996. Asimismo, William Robinson: "El rol de la democracia en la política exterior norteamericana y el caso Cuba", en Haroldo Dilla (compilador): La democracia en Cuba y el diferendo con los Estados Unidos, Centro de Estudios sobre América/ Editorial de Ciencias Sociales, La Habana, 1996. Según este autor el término "poliarquía" fue definido por el politólogo Robert Dahl como un sistema político en el cual gobierna un pequeño grupo, y la participación de las masas en la toma de decisiones se limita a seleccionar la dirigencia en elecciones cuidadosamente manipuladas por las elites competidoras.
} 
contribuye a explicar los marcados déficits institucionales, funcionales, económicos, sociales, ecológicos, democráticos y en sus correspondientes inserciones en la "economía mundo" que, de manera más o menos pronunciada, en la actualidad exhiben todos los proyectos de integración multinacional que se están desarrollando en diversas regiones de América Latina y el Caribe: el SICA, la CARICOM, la CAN y el MERCOSUR.

Esos déficit también se expresan en la dinámica de la Asociación Latinoamericana de Integración (ALADI) y en el funcionamiento de todos los organismos de concertación política y cooperación económica que, con el propósito declarado de impulsar su integración regional, formaron los gobiernos latinoamericanos y caribeños durante las décadas de 1970, 1980 y 1990. O sea, el Sistema Económico de América Latina y el Caribe (SELA), el Mecanismo Permanente de Consulta y de Cooperación Política (conocido como el Grupo de Río), y la Asociación de Estados del Caribe (AEC), respectivamente. Esta última compuesta por todos los países centroamericanos (incluido Panamá) y del Caribe insular (Antigua, Bahamas, Barbados, Dominica, Granada, Jamaica, San Kits y Nevis, San Vicente y las Granadinas, Trinidad y Tobago, Haití) y continental (Belice, Guyana y Surinam), así como por los gobiernos integrantes del ahora virtualmente extinto Grupo de los Tres (G3): Colombia, Venezuela y México.

Como bien se ha dicho, la superposición y solapamiento institucional de esas organizaciones regionales, junto a la escasa capacidad de los gobiernos latinoamericanos y caribeños para abordar acuerdos conjuntos en otras áreas (cual son las políticas exteriores, de defensa y de seguridad), a "las acciones segmentadas" y a las "sustituciones de competencia" de los organismos políticos y económicos existentes por parte de los grupos ad hoc que se han formado en diversas oportunidades (cual fue el caso del llamado Grupo de Cartagena formado con el único propósito de renegociar la "deuda externa"), han acentuado "el riesgo de dispersión que afronta 
todo proceso de integración multinacional"; incluso los que han elegido "el sector económico como base esencial de [sus] procesos respectivos, aunque se invoquen frecuentemente lazos históricos y conveniencias utilitarias o de otra indole para sustentar la 'idea fuerza' de la integración"; ${ }^{32}$ cuales fueron los casos de la entonces llamada Comunidad Económica Europea (ahora UE) y de los proyectos integracionistas surgidos en América Latina y el Caribe al calor del "desarrollismo" y de la llama "industrialización por sustitución de importaciones" (ISI) estimulados por la Comisión Económica para América Latina y el Caribe de la ONU (CEPAL).

A tal dispersión también han contribuido la multiplicidad y simultaneidad de las negociaciones que han desarrollado o están desarrollando de manera bilateral, plurilateral o multilateral los gobiernos latinoamericanos y caribeños entre sí (como los Acuerdos de Libre Comercio firmados por México con Centroamérica y con Chile o el Acuerdo de Libre Comercio entre la CAN y el MERCOSUR), en la Organización Mundial del Comercio (OMC), al igual que con la Unión Europea (UE), con Canadá y con Estados Unidos. Cual indiqué desde hace varios años, estas últimas negociaciones (ahora vinculadas a la protocolización del ALCA), junto a las negativas tendencias estructurales de las economías y las sociedades latinoamericanas y caribeñas, colocan a todos los proyectos de integración multinacional que se están desarrollando en el centro y el sur del hemisferio occidental en la disyuntiva histórica de avanzar hacia una integración multinacional autónoma que, al menos, le garantice la diversificación de sus dependencias externas, o aceptar su "integración subordinada" a la potencia hegemónica en ese hemisferio. Mucho más, porque a diferencia de otros momentos históricos (en los que la "idea fuerza de la integración había sido un patrimonio exclusivo de las repúblicas latinoamericanas" observado con displicencia o reticencia por los cír- 
culos de poder estadounidenses), a partir de la Iniciativa de las Américas lanzada por el presidente George H. Bush (1989-2003), del Tratado de Libre Comercio de América del Norte (TLCAN) firmado entre Canadá, Estados Unidos y México en los primeros años de la década de 1990 y de las negociaciones del ALCA impulsadas por la administración del demócrata William Clinton (1993-2001), esa potencia ha asumido "un papel protagónico directo y como actor principal en ese proceso hemisférico". ${ }^{33}$

Lamentablemente hacia la antes referida "integración subordinada" o "coercitiva" (o hacia esa virtual "recolonización" del continente) también apuntan las tendencias actuales (Calloni y Ducrot, 2004). Sobre todo porque-como se indicó en el acápite anterior- las capacidades de negociación colectiva de América Latina y el Caribe con Estados Unidos se han visto nuevamente menguadas -además de por los acuerdos "extraeconómicos" y "económicos" apuntados en el acápite anterior- por las discrepancias existentes entre diversos gobiernos latinoamericanos y caribeños respecto al contenido y alcance de la integración hemisférica, incluida la discusión respecto al llamado "trato especial y diferenciado" a las naciones de menor desarrollo relativo de la región (Giacalone, 2003, p. 69-85). También se han visto reducidas por los sucesivos Acuerdos de Libre Comercio signados por Estados Unidos con Chile (2003) y, más recientemente, con Centroamérica y República Dominicana. Asimismo, por las negociaciones bilaterales que, con igual fin, está desenvolviendo la Casa Blanca con buena parte de los gobiernos andinos y, específicamente, con Colombia, Ecuador y Perú.

Sin negar la subsistencia de algunas contradicciones (cuales son las existentes entre los actuales gobiernos de México y Estados Unidos respecto a la vigencia del TIAR y la inclusión o no de los temas migratorios en la agenda de "seguridad cooperativa" o de la "seguridad multidimensional"), ${ }^{34}$ 
merece resaltar que esos acuerdos y negociaciones de "libre comercio" (incluido el TLCAN) han sido antecedidos por la aceptación tácita o expresa, en mayor o menor grado, por parte de los gobiernos latinoamericanos implicados de las sesgadas nociones sobre "la democracia de libre mercado" y "la seguridad interamericanas" diseñadas por los círculos de poder estadounidenses y, más recientemente, por su participación, de manera más o menos directa, en las superpuestas guerras contra "el narcotráfico" y contra "el terrorismo" que, desde el 11 de septiembre del 2001, de manera oportunista viene impulsando la administración de George W. Bush. Así lo demuestran, entre otros hechos, la implementación del Plan Colombia (aprobado por el presidente William Clinton y ahora rebautizado por el actual gobierno colombiano con el nombre de Plan Patriota) y de la llamada Iniciativa Andina Antidrogas (más conocida como Iniciativa Regional Andina o, más propiamente, andinoamazónica) impulsada por la actual administración republicana desde los primeros meses del año 2001 (Petras, 2001, p. 3-11). ${ }^{35}$

Aunque no son parte de la misma, los fundamentos esenciales de este último proyecto político-militar, esencialmente contrainsurgente, fueron respaldados por los presidentes de Guatemala, Honduras, El Salvador, Nicaragua y Costa Rica en la Cumbre Centroamericana efectuada en Roatán, Honduras, el 18 de marzo del 2003. Igualmente, en su reunión posterior con el actual presidente de Colombia, Álvaro Uribe (2002-...), impulsor de una mal definida y peor aplicada noción sobre "la seguridad democrática" (Pizarro Leongómez, 2003, p. 4-17), así como de la "internacionalización" del conflicto interno colombiano. Como han señalado algunos autores, no obstante algunos avances puntuales en la llamada "integración comercial" centroamericana registrados en los años más recientes (Ramírez López, 2002), ${ }^{36}$ esa subordinación a la estrategia

35 También puede consultarse: Pronunciamiento del Grupo de Monitoreo del Plan Colombia en Ecuador. Quito, 5 de mayo del 2004.

36 Asimismo, de la propia autora puede consultarse: “La Integración Centroamericana en el 2002: ¿Se consolida o se desvirtúa ante el Tratado de Libre Comercio con los Estados Unidos?, Instituto de Investigaciones Económicas. UNAM, 2003. 
de seguridad de la potencia hegemónica en el hemisferio occidental, junto a la firma del Ilamado Acuerdo de Libre Comercio entre Centroamérica y los Estados Unidos (CAFTA, por sus siglas en inglés), a la persistente dependencia de esa región de los flujos comerciales e inversionistas de esa potencia imperialista, y a la ratificación de los enunciados del llamado Plan Puebla Panamá (impulsado por el gobierno de México y por los demás gobiernos centroamericanos con el evidente apoyo de la Casa Blanca) "marcará significativamente las relaciones de Centroamérica con los EE.UU.", debilitará aún más el SICA -en especial su Secretaría General y su Secretaría de Integración Económica (SIECA)-, así como dejará "muy mal parada a la integración como instrumento alternativo para mejorar la posición regional ante los Estados Unidos" ${ }^{37}$ Esto -y los profundos cambios conceptuales y prácticos que se han producido en su "integración económica" - Ilevaron al economista costarricense Álvaro de la Ossa a afirmar certeramente que "Centroamérica está cada vez menos integrada y más globalizada" (Ossa, 2003, p. 60-68).

Lo anterior, junto al chantaje de perder en el año 2005 (fecha en que vence la llamada Autoridad para la Promoción del Comercio -TPA por sus siglas en inglés- entregada por el congreso estadounidense al presidente George W. Bush en agosto del 2002) las ventajas comerciales obtenidas por los países centroamericanos y caribeños beneficiaros de la Iniciativa para la Cuenca del Caribe (ICC) unilateralmente promulgada desde 1983 por los Estados Unidos, virtualmente anula las posibilidades futuras de avanzar en lo que en su momento se llamó "la Alianza Estratégica entre Centroamérica y el Caribe". Mucho más por las claras divergencias que existen en el enfoque del "libre comercio" y de "la seguridad hemisférica" entre los gobiernos centroamericanos y los de la absoluta mayoría de los

\footnotetext{
37 Daniel Matul: “Estados Unidos y Centroamérica: La agenda bilateral (1997-2003)”, ponencia presentada al Seminario Internacional "Regionalismo, Seguridad Regional y Sociedad Civil en el Gran Caribe y el Nuevo Entorno Mundial", La Habana, Cuba, 25 al 27 de Febrero de 2004.
} 
15 países del Caribe insular y continental miembros plenos del CARICOM. Desde la suscripción del Tratado Revisado de Chaguaramas del 2001, estos últimos han venido impulsando lo que -en la Cumbre de Grande Ansen, Granada, de 1989- se llamó "un Mercado y Economía Únicos del Caribe" (CMSE, por sus siglas en inglés) (Haughton-Cárdenas, 2004, p. 4-8).

Como consecuencia de esa aún inconclusa decisión, (cuya culminación está prevista para el 2005), a diferencia de Centroamérica, el CARICOM -además de impulsar sus relaciones conjuntas con otros países de América Latina, África y Asia (en especial, con los integrantes del llamado Grupo África, Caribe, Pacífico signatarios de los acuerdos de Cotonou y con el Grupo de los 90 de la OMC)- ha mejorado significativamente sus capacidades de negociación conjunta en diferentes foros internacionales (como la OMC), hemisféricos (las Cumbres de las Américas, la OEA y las negociaciones del ALCA) y en los que se discute lo que Gustavo Magariños llama su "integración a distancia" con la UE. ${ }^{38}$ Es decir, sus vínculos con la hasta hace poco denominada "Europa de los 15" (ahora "Europa de los 25") en el marco de los llamados Acuerdos de Cotonou, sucedáneos, a partir del año 2000, de las ya extintas Convenciones de Lomé signadas entre la UE y sus antiguas colonias de Asía, el Caribe y el Pacífico (ACP). Asimismo, recientemente el CARICOM creó la Corte de Justicia del Caribe investida de la jurisdicción obligatoria y exclusiva para resolver las disputas que puedan presentarse entre sus países miembros. Esa decisión -además de eliminar los últimos vestigios de su pasado colonial frente al Reino Unido- constituyó un nuevo avance en la prolija institucionalidad políticojurídica del CARICOM (García Lorenzo, 2004, p. 15-20).

\footnotetext{
38 Según indica Gustavo Magariños en su obra ya mencionada, la "integración a distancia" alude a los acuerdos preferenciales y/o de libre comercio de carácter transcontinental, como los que han signado algunos gobiernos latinoamericanos (México, Chile) y caribeños (los integrantes del CARICOM) con la UE. Por ello, en este último caso, incluyó los aún vigentes, pero próximos a finiquitar Acuerdos de Cotonou firmados en el año 2000 entre decenas de países del Grupo ACP (Asia, Caribe y Pacífico) con los 15 países que en ese momento integraban la UE.
} 
A lo antes dicho hay que agregar las posiciones conjuntas asumidas por los gobiernos integrantes de esa comunidad caribeña en defensa de los intereses de los pequeños Estados Insulares en Vías de Desarrollo (SIDS, por sus siglas en inglés) de esa región y de otras partes del mundo, al igual que su firme rechazo a la guerra desatada por Estados Unidos e Inglaterra contra Irak, así como a la pretensión de la primera de esas potencias imperialistas de condicionar los múltiples acuerdos existentes en materia de la lucha contra el tráfico de drogas y otros delitos conexos a la aceptación compulsiva por parte de los gobiernos caribeños de los llamados BIA aludidos en el acápite anterior. ${ }^{39}$ Esas posturas concertadas e independientes del CARICOM respecto a los dictados de la Casa Blanca también se expresaron, a partir de febrero del 2004, en el rechazo de sus miembros a la ocupación militar de Haití por parte de los Estados Unidos, Canadá y Francia, a la deposición ilegal del presidente constitucional haitiano, Jean Bertrand Aristide, al igual que a los contenidos del informe de la mal llamada Comisión para la Ayuda a una Cuba Libre, aprobado por el gobierno de George W. Bush a comienzos de mayo del 2004 con el descarado propósito de acelerar, por diferentes medios (algunos aún ocultos), lo que mañosamente denominan "la transición democrática en Cuba" ${ }^{40}$

Sin embargo, nada de lo antes dicho debe entenderse como que el autor de este ensayo tiene una visión idílica respecto al futuro inmediato de la integración multinacional del Caribe insular y continental. Por el contrario, junto a otros autores, es consciente de los inmensos desafíos que en el futuro próximo tendrá que enfrentar ese proyecto integracionista. Entre ellos -en palabras de la economista cubana Tania García Lorenzo"la asincronía de los ciclos productivos"; "los desequilibrios macroeconómicos" que de manera distinta afectan a los países de esa

39 Gisela García Rivera: ob. cit.

40 IPS: "Bush refuerza embargo", en IPS: Revista Semanal, La Habana, 3 al 9 de mayo de 2004. 
región; la inadecuada coordinación de las políticas económica, social, fiscal y monetaria entre sus autoridades políticas y económicas; y el escaso peso que -no obstante su repunte reciente- aún tienen "el comercio y las inversiones intraregionales" ${ }^{41}$

Esas debilidades interactúan con las amenazas que plantean a la integración multinacional caribeña la fortalecida estrategia de dominación de los Estados Unidos sobre esa subregión (redefinida por George W. Bush, como "la tercera frontera" de su país); las diferencias de enfoques existentes entre sus gobiernos y los de otros países del hemisferio occidental (entre ellos, los integrantes del MERCOSUR) respecto al llamado "trato especial y diferenciado" que se discute en las inconclusas negociaciones del ALCA; así como con relación el anunciado abandono por parte de la UE de los acuerdos preferenciales que, durante muchos años, guiaron su relación con el Caribe angloparlante y su sustitución por la mal llamada "reciprocidad" entre las partes . Estos últimos factores -junto a la constante expropiación por parte de los "países capitalistas centrales" del excedente económico generado por las naciones del Caribe, al sistemático robo de sus cerebros y de su fuerza de trabajo más calificada, así como la consiguiente incapacidad de disponer de fuentes propias de acumulaciónen el futuro próximo pudieran provocar el fortalecimiento de las ya marcadas dependencias estructurales del Caribe respecto a las principales potencias imperialistas y especialmente a Estados Unidos. Todas esas tendencias adversas Ilevaron al actual Primer Ministro de Guyana, Bharrat Jagdeo, a afirmar que "el tiempo no está a favor del CARICOM". ${ }^{42}$

Una expresión semejante podría utilizarse para definir las debilidades y amenazas de todo tipo que está confrontando la CAN. Ambas se refuerzan mutuamente por la inestabilidad política de los países del área,

\footnotetext{
41 Tania García Lorenzo: Ob. cit. 42 Ídem.
} 
al igual que por la evidente pérdida de la voluntad y la cohesión políticas entre la mayoría de los actuales gobiernos de sus Estados miembros (Bolivia, Colombia, Ecuador, Perú y Venezuela) para impulsar de forma autónoma el proyecto de integración multinacional que redefinieron en abril de 1996. ${ }^{43}$ Como ya está indicado, a ello contribuye la decisión de los actuales gobiernos de Colombia, Ecuador y Perú (y, llegado el caso, también de Bolivia) de negociar en forma bilateral $-y$, por tanto, desconociendo la institucionalidad de la CAN y la firma postura del gobierno de la República Bolivariana de Venezuela- acuerdos de libre comercio con los Estados Unidos. También la creciente subordinación de esos gobiernos a la Estrategia de Seguridad imperial de los Estados Unidos bajo el renovado chantaje de perder, en el 2005, las facilidades de acceso al mercado estadounidense que, años atrás, le ofreció la Ley de Preferencia Arancelaria Andina y Erradicación de la Droga (ATPDEA, por sus siglas inglés) aprobada unilateralmente por el Congreso estadounidense como parte de la "guerra contra el narcotráfico" impulsada por las administraciones de los republicanos Ronald Reagan (1981-1989) y George H. Bush (1989-1993).

A lo antes dicho habría que agregar las dificultades de los integrantes de la CAN para avanzar en las negociaciones de un Acuerdo de Asociación con la UE (Cardona C., 2004, p. 117-124); la pobre dinámica de sus vinculaciones político-económicas con las naciones integrantes del llamado "Anillo del Pacífico"; su creciente dependencia de los flujos inversionistas de Estados Unidos; así como las escasas articulaciones económicascomerciales entre los propios miembros de la CAN y de estos con otros países latinoamericanos y caribeños, incluidos los actuales miembros del MERCOSUR. Esto último genera un justificado escepticismo respecto al futuro del Acuerdo de Libre Comercio entre esta agrupación integracionista y la CAN que -a instancias de las últimas Cumbres Suramericanas- se 
firmó el 18 de octubre del 2004 en la XIII Reunión de Consejo de Ministros de la ALADI efectuada en Uruguay. ${ }^{44}$ Ese escepticismo es mucho mayor respecto a las posibilidades de avanzar en la formación del Área de Libre Comercio Suramericana (ALCSA) propugnada infructuosamente por el gobierno de Brasil desde el año 1993 (Bandeira, 2003, p. 142-157).

Sin embargo, esa idea fue acogida por los integrantes del MERCOSUR en la Cumbre de ese organismo efectuada, en Asunción, Paraguay, a mediados del año 2003. Es decir, poco después de los sucesivos ascensos a la presidencia de Luiz Inácio (Lula) Da Silva en Brasil y de Néstor Kirchner en Argentina, así como de la victoria electoral del actual presidente paraguayo Nicanor Duarte Frutos (Bizzozero, 2003, p. 128-142). A pesar del escaso peso de ese último país en las principales decisiones de ese acuerdo integracionista, sin dudas, la positiva proyección externa del gobierno de Duarte -junto a la Alianza Estratégica establecida por los presidente de Argentina y Brasil en junio del 2003 y a la reciente victoria del candidato presidencial del Frente Amplio-Encuentro Progresista-Nueva Mayoría de Uruguay, Tavarés Vázquez (31 de octubre del 2004)- en el futuro inmediato debe facilitar el impulso de los principales contenidos del Programa para la Consolidación de la Unión Aduanera y el Mercado Común: Objetivo 2006, elaborado por la diplomacia brasileña como plataforma para impulsar la recién fundada la Comunidad Suramericana de Naciones y, por ende, sus relaciones con todos los países de América del Sur. Especialmente, con el MERCOSUR.

En consecuencia, ese esquema integracionista comenzó a delinear acciones dirigidas a resolver las asimetrías de desarrollo existentes entre sus miembros; a la definición de sus objetivos políticos, culturales y de seguridad; a la articulación de sus planes de desarrollo, así como de otros proyectos regionales (como la Integración de la Infraestructura Regional 
Suramericana) que pudieran contribuir a concretar el ya mencionado Acuerdo de Libre Comercio CAN-MERCOSUR en los próximos tres lustros, así como a impulsar el funcionamiento de la Comunidad Suramericana. Obviamente, el éxito o el fracaso de ambos empeños dependerán, en primer lugar, de las capacidades que tenga el MERCOSUR para superar sus propias debilidades.

Entre ellas, la indefinición de un arancel externo común; la debilidad de su infraestructura institucional; la ausencia de un orden jurídico regional capacitado por la garantizar el cumplimiento de sus normativas; la carencia de un régimen para la promoción de inversiones intraregionales, así como de un Parlamento elegido de manera directa por los ciudadanos de ese espacio integracionista. Igualmente, el inadecuado funcionamiento de su Foro Consultivo Económico y Social, al igual que de su Comisión Parlamentaria Conjunta. A ellos se une la inexistencia de acuerdos en el campo educativos, migratorio y de la cooperación judicial que faciliten los trámites y movimientos de los ciudadanos de los países miembros del acuerdo, así como de una política de ciencia y técnica común y de una efectiva política de defensa y seguridad compartida por todos sus miembros. ${ }^{45}$

Esas y otras carencias que veremos después, junto a las propias debilidades del actual gobierno brasileño -cuyas bases de sustentación sociopolíticas y su gabinete se encuentra divididos con relación a la postura a adoptar frente al ALCA y otros temas políticos, económicos y sociales internos y hemisféricos- (Margolis, 2004), y a la aún irresuelta crisis económica y social que vienen sufriendo, con mayor o menor intensidad, todos los países de la región (atenazados por voluminosas deudas externas y por sus constantes negociaciones con el FMI) objetivamente debilitan las resistencias de los gobiernos integrantes del MERCOSUR a la política estadounidense hacia el hemisferio occidental. Así lo demuestran los costos políticos que, 
en sus relaciones con el CARICOM, han tenido que pagar los gobiernos de Argentina y Brasil por involucrarse en la ocupación militar-policial de Haití. Igualmente, por no haber adoptado una actitud más enérgica en las negociaciones del ALCA. Esto último a pesar de que diferentes estudios ex antes han demostrado empíricamente los altos costos que ese acuerdo tendría para la posición estratégica y las economías de Brasil y Argentina: los dos pilares del MERCOSUR. ${ }^{46}$

Según algunos pronósticos, esta situación de debilidad relativa frente a los Estados Unidos pudiera registrar algunos cambios en la medida que se consolide el gobierno de Tavaré Vázquez (quien -a diferencia de su predecesor en el cargo- ha reiterado su claro compromiso con el fortalecimiento del MERCOSUR) y si se aprueba (como todo parece indicar) el ingreso del gobierno de la República Bolivariana de Venezuela como Miembro Asociado del MERCOSUR. Ambos acontecimientos y sus crecientes debilidades internas, podrían propiciar un mayor acercamiento del gobierno de Bolivia (actualmente presidido por Carlos Mesa) hacia este último proyecto de integración multinacional. Sobre todo porque -a diferencia de otros países andinos- en la actualidad tanto Argentina, como Brasil tienen un alto peso en el comercio exterior boliviano. ${ }^{47}$ Y porque la ya mencionada Cumbre del MERCOSUR efectuada a mediados del año 2003, aprobó un Programa de Acciones dirigidas a atender los problemas de los países en desarrollo sin litoral (Bolivia, Paraguay) y los vinculados al tránsito entre los océanos Atlántico y Pacífico de Argentina, Brasil, Chile y Perú. ${ }^{48}$

En la opinión de algunos analistas (Casals Llano, 2003), la confluencia de todos esos factores, junto a su rechazo más o menos radical del ALCA y de cualquiera de sus modalidades, podría facilitar los profundos cambios

\footnotetext{
46 Luiz Alberto Muñiz Bandeira: ob. cit., pp.152-154.

47 Diego Cardona C.: ob. cit.

48 Lincoln Bizzozero: ob. cit., p. 140.
} 
que demanda el MERCOSUR. A los señalados en párrafos precedentes habría que agregar la necesidad que tiene ese acuerdo de integración multinacional de otorgarle en su funcionamiento una mayor prioridad a los aspectos políticos y a otras dimensiones "no económicas"; así como de avanzar en la coordinación de sus sectores productivos y en el establecimiento de un Programa de Coordinación y Convergencia Macroeconómica que, en el futuro próximo, pueda concluir con el establecimiento de una moneda común diferente al dólar y al Euro. Igualmente, en el fortalecimiento institucional del bloque y de las instancias jurídicas (el Tribunal Permanente de Revisión que comenzó a funcionar en Agosto del 2004) que permitan la solución de los conflictos que frecuentemente se han presentado y que en el futuro se presentarán entre sus Estados miembros; en el fortalecimiento de sus capacidades para negociar con otros países y bloques regionales y extra regionales (como la UE); al igual que el despliegue de políticas económicas y sociales dirigidas "a la eliminación de las brutales diferencias de ingresos existentes en [la población] de la región"; en particular en los principales países integrantes del MERCOSUR: Argentina y Brasil, país que -como bien ha recordado el economista cubano Jorge Casals- es uno de los que peor distribuye sus ingresos en todo el mundo. ${ }^{49}$

\section{A modo de conclusión: hacia un nuevo paradigma de la integración multinacional latinoamericana y caribeña}

Estas últimas afirmaciones me colocan en mis definiciones acerca de lo que he venido denominando "un nuevo paradigma para la integración multinacional latinoamericana y caribeña"; cuyo punto de partida tiene que ser-como veremos más adelante- el rechazo de los PAE de factura neoliberal y neoconservadora impulsados por el Departamento del Tesoro 
de Estados Unidos, por el FMI y por el BM, al igual que una radical reformulación de "los proyectos de desarrollo hacia fuera" que -bajo los conceptos del "regionalismo abierto" - ha venido impulsando la CEPAL en los dos lustros más reciente (Cepal, 1994).

Como indiqué a fines del siglo pasado, ${ }^{50}$ es cierto que cuando, en 1994, ese organismo de la ONU formuló ese programa lo hizo criticando las ostensibles deformaciones creadas en las economías y en las sociedades latinoamericanas y caribeñas por los esquemas de integración fundados en el "proteccionismo", en la Ilamada ISI y en las nociones "desarrollistas" vigentes durante las décadas de 1960 y 1970. Igualmente, buscando resolver los profundos problemas estructurales que se habían develado durante la llamada "década pérdida" (1980) para el desarrollo económico-social de América Latina y el Caribe. También pensando en la indisoluble articulación que, en las condiciones de "la globalización", tenía que existir entre la integración regional y lo que previamente había llamado: "la transformación productiva con equidad". ${ }^{51}$

Pero también es cierto que -según los propios datos empíricos aportados por la propia CEPAL y por otros organismos de la ONU, como el PNUD, la FAO y la UNICEF- el decenio transcurrido desde entonces hasta acá demuestra que en América Latina y el Caribe la miseria, la inequidad y la llamada "deuda social", lejos de disminuir, se ha profundizado. ${ }^{52}$ Que la transformación productiva tampoco ha ocurrido y que, en los casos en que se ha "avanzando" en esa dirección, se ha hecho a costa de deteriorar aún más los sistemas ecológicos-ambientales del continente en tanto

el esfuerzo exportador de la mayoría de los países latinoamericanos y caribeños se han dirigido hacia sectores con un uso intensivo de recursos naturales o

\footnotetext{
50 Luis Suárez Salazar: El siglo XXI: Posibilidades y desafíos para la Revolución cubana, ed. cit. 51 CEPAL: ob. cit.

52 Ximena de la Barra, Asesora Regional de la UNICEF: “¿Quién debe y quién paga? La deuda social tiene muchos acreedores. Los principales acreedores son los niños", ponencia presentada al Seminario Internacional "Agenda Latinoamericana Siglo XXI", FLACSO/UH, La Habana, 8 de junio del 2004.
} 
vinculados a industrias [cual es el caso de las llamadas "maquilas"] ambientalmente sensibles o sucias. ${ }^{53}$

Igualmente es cierto -como hemos visto a lo largo de este documento- que el llamado "regionalismo latinoamericano y caribeño", aunque ha registrado ciertos avances en una u otra subregión (como son los casos del Caribe y de ciertas áreas del funcionamiento del MERCOSUR), está muy lejos de las necesidades de la integración multinacional que demanda el continente. Y ello es así, entre otras cosas, porque las fuerzas centrífugas generadas por la apertura unilateral de América Latina y el Caribe hacia el exterior bajo los "presuntos imperativos de la globalización" (Estay, 1995), han preponderado sobre las fuerzas centrípetas que, en teoría, deberían impulsar constantemente el desarrollo de cualquier proceso de integración multinacional..$^{54}$ Por ello, se puede decir que en ese continente hay cada vez más "apertura" y menos "regionalismo".

Desde mi punto de vista, en la base de esa situación se encuentra el hecho real de que -pese a su retórica- todos los proyectos de integración latinoamericanas y caribeña que se reformularon (el SICA, el CARICOM y la CAN) o se emprendieron (el MERCOSUR) en la década de 1990 se han realizado a expensas de lo que Raúl Prebish llamó "el desarrollo hacia dentro" o, si se prefiere, sacrificando lo que, en 1991, Osvaldo Sunkel redefinió como "el desarrollo desde dentro" (Sunkel, 1991). Y no podía ser de otra forma porque, como previeron algunos especialistas (Regueiro, 1994), en última instancia, en mayor o menor grado, todos esos proyectos integracionistas han estado condicionados y lastrados por las desastrosas políticas económicas, industriales, sociales, culturales y ambientales aplicadas por los diversos gobiernos que, en los últimos lustros, han represen-

53 CEPAL: Panorama social de América Latina, Santiago de Chile, 2000. Enunciados parecidos se pueden encontrar en los informes al respecto de CEPAL en el 2001, 2002 y 2003.

54 Gustavo Magariños: ob. cit. 
tado y defendido los intereses de las clases dominantes en América Latina y el Caribe. En especial, por los ingentes esfuerzos por esos gobiernos para "honrar" a toda costa la impagable deuda externa acumulada desde la década de 1970, al igual que para aplicar de manera fundamentalista los PAE facturados por el Departamento del Tesoro de los Estados Unidos y por los organismo financieros internacionales (FMI y BM) impulsores del llamado "Consenso de Washington" de 1990. ${ }^{55}$

De más está decir que esos PAE sólo trataron y tratan de garantizar el crecimiento o, de manera más precisa, la reproducción continua y ampliada del capitalismo dependiente instaurado en la mayor parte de los países latinoamericanos y caribeños. Mucho más porque, en las condiciones creadas por la llamada "globalización neoliberal", esa forma de reproducción del capitalismo periférico ha estado y está asociada al libre funcionamiento de la economía de mercado, a la minimización o "refundación" del papel del Estado (cada vez más constreñidos a sus funciones represivas), a la desnacionalización de las riquezas, a la privatización de la mayor parte de los servicios públicos y de buena parte de los servicios sociales; en fin a la creación de "un clima de confianza" para la propiedad privada y para el incremento de las tasas de ganancias de los capitales internos y externos (productivos o especulativos) que se inviertan en la región.

Como consecuencia, la protección y conservación de la naturaleza, de la biodiversidad, así como del medio ambiente de las ciudades, de las cuencas hidrográficas y de las costas marítimas, al igual que la imprescindible ampliación del mercado interno -al que se refiere las condiciones de vida de decenas de millones de personas- han sido y todavía son variables absolutamente subordinadas y secundarias respecto al propósito de las principales potencias imperialistas (y sus clases y grupos dominantes) de crear nuevos ejes de acumulación capitalistas acordes con las 
modificaciones que ellas mismas han impulsado en la división internacional del trabajo. Con independencia de las resistencias estatales (y no estatales) que perduran, en su intencionada dinámica, esa "división del trabajo" tiende a fortalecer la "integración coercitiva" del continente al imperialismo norteamericano.

Por todo lo antes dicho y por otros elementos excluidos en aras de la síntesis, considero que -tal cual plantearon en su ya mencionada Declaración Conjunta respecto al ALBA los presidentes Hugo Chávez y Fidel Castro ${ }^{56}$ - el nuevo paradigma de integración multinacional que demanda América Latina y el Caribe, tiene que tener como base la crítica teórico-práctica de ese "modelo de acumulación"; el abandono de todas las negociaciones dirigidas a institucionalizar el ALCA o cualquier de sus modalidades; la renegociación de la deuda externa en condiciones que aseguren, antes que todo, la cancelación de la "deuda social" acumulada en el continente y el consiguiente despliegue de proyectos de "desarrollo hacia dentro" que garanticen, en primer lugar, la protección eficaz y la satisfacción de todos los derechos humanos (económicos, sociales, culturales, civiles y políticos, individuales y colectivos, incluido el derecho al disfrute de un medio ambiente sano para las actuales y futuras generaciones y los derechos de las naciones originarias) de todos y todas los/las habitantes de América Latina y el Caribe. En segundo, la potenciación y la defensa de los ingentes recursos humanos, naturales, ecológicos y económicos con que cuenta el continente. En tercer lugar, una "relación filial" con la naturaleza y sus diversos ecosistemas. Y, en cuarto, la construcción de democracias participativas y socialmente representativas capaces de superar las ostensibles carencias que, incluso según sus defensores, caracterizan a las "democracias representativas" que actualmente preponderan en la región (Caputo, 2004). 
Los gobiernos resultantes de esos procesos políticos participativos y socialmente representativos también deberán ser capaces de proyectar políticas internas y exteriores que privilegien los componentes políticos, sociales, económicos, ecológicos y jurídicos y de la llamada "seguridad multidimensional" (incluida la "seguridad ciudadana") de factura latinoamericana y caribeña, así como que garanticen, junto a ello, los legítimos intereses de defensa individuales y colectivos de todas los Estados nacionales situadas al sur del río Bravo y de la península de La Florida. Asimismo; el desarrollo de vínculos de cooperación en esos y otros campos con las demás naciones del mundo subdesarrollado (entre ellas, las que aún no han adquirido la categoría de Estados-nacionales, como es el caso de Puerto Rico y de otras islas del Caribe aún sometidas a formas coloniales de dominación); al igual que la imprescindible diversificación de las relaciones estratégicas de América Latina y el Caribe con las otras potencias (diferentes a Estados Unidos) integrantes de la pentarquía o el sexágono del nuevo orden mundial.

Un paso ineludible en esas direcciones tiene que ser, cuando menos, el restablecimiento del funcionamiento cabal y democrático de todos los organismos político-diplomáticos surgidos en la región (desde el SELA hasta la ALADI, pasando por el Grupo de Río y por la AEC) con el propósito declarado (pero no siempre cumplido) de impulsar la concertación política, la cooperación económica, así como la integración multinacional de América Latina y el Caribe. Sin embargo, a diferencia de lo que ocurre en la actualidad, esas instituciones o las nuevas organizaciones multilaterales que se han formado (como la Comunidad Suramericana) o que en el futuro se formen (cual pudiera ser una Asociación de Estados Latinoamericanos y Caribeños), no deben ser visualizados como órganos técnico-burocráticos o sólo destinado a la concertación de posiciones políticas, sino como las imprescindibles instancias supranacionales que, poco a poco, garanticen 
la elaboración soberana de una nueva soberanía continental, así como la armonización político-jurídica y técnico-económica de todos los esquemas subregionales de integración multinacional que se desarrollan en la actualidad. Igualmente, deberán ser las encargadas de dialogar y negociar colectivamente con las demás instituciones del sistema internacional (incluidas la OMC, el FMl y el BM), así como con los otros esquemas de integración multinacional que se desarrollan en otras zonas del mundo desarrollado (como la UE) o subdesarrollado, cuales son los casos de la Asociación de Naciones del Sudeste Asiático (ASEAN) y de otros proyectos integracionistas que se están desarrollando en diferentes regiones de África.

Esos organismos multilaterales latinoamericanos y caribeños también tendrían la responsabilidad de crear y de legitimar constantemente las instancias parlamentarias (el Parlamento Latinoamericano y Caribeño) y de participación de la sociedad civil que garanticen su funcionamiento democrático, así como la fundación y consolidación de los órganos jurídicos (como pudiera ser un Tribunal Latinoamericano y Caribeño) que permita la solución de las disputas y conflictos que inevitablemente se producirán entre los países integrantes de la nueva institucionalidad integracionista, al igual que entre estos y las empresas extranjeras, estrictamente nacionales, multinacionales y trasnacionales, que inviertan en la región. La acción de estas empresas deberá estar regulada con vistas a evitar la constante descapitalización del continente, así como las agresiones a los recursos humanos, a las empresas (estatales y privadas) latinoamericanas y caribeñas, al medio ambiente y a la biodiversidad que éstas sistemáticamente perpetran en su desmedida búsqueda de ganancias.

Obviamente, todo lo antes dicho implicará la denuncia del TIAR y de los acuerdos militares y de seguridad y de los BIA suscriptos a su amparo entre los gobiernos latinoamericanos y caribeños con el gobierno de Estados Unidos. Asimismo, la extinción de la OEA y de todos los organis- 
mos del Sistema Interamericano (como la Junta Interamericana de Defensa) históricamente impulsados por los grupos dominantes en esa potencia imperialista con vistas a complementar sus bicentenarias estrategias de dominación sobre América Latina y el Caribe. En ese escenario, las Cumbres de las Américas tendrían una entidad y una cobertura hemisférica similar a las que ya han adquirido las Conferencias de Primeras Damas, Esposas y Representantes de Jefes de Estado y Gobiernos de las Américas. ${ }^{57}$ Por tanto, al igual que las Cumbres Iberoamericanas, sólo serán espacios para desarrollar el otrora llamado "dialogo Norte-Sur" entre absolutamente todos los 35 Estados-nacionales actualmente existentes en el hemisferio occidental y, en el futuro más o menos próximo, de los otros Estadosnacionales que se formen como consecuencia de la postergada conclusión de la total descolonización del Archipiélago de las Antillas y del territorio de Cayena, posesión colonial francesa ubicada en el nororiente de América del Sur.

Tengo conciencia que algunos lectores podrán pensar que formulaciones como las anteriores son una utopía irrealizable, cargadas de una dosis de voluntarismo. Mucho más en las adversas condiciones creadas por "la globalización" o por el llamado "imperialismo global". Y no les faltaría razón si se aproximan de manera determinista a las tendencias del pasado y a las preponderantes en la actualidad. Sin embargo, reitero que la mirada desde la prospectiva crítica y participativa que han guiado estas reflexiones parten de la base de que los múltiples "sujetos de acción" y los diversos "actores sociales" que representan los intereses de la mayoría de

\footnotetext{
57 Ese es el nombre actual del inicialmente llamado Encuentro Latinoamericano y del Caribe de Primeras Damas. La primera edición de esos pocos conocidos encuentros (en los que ahora también participan representantes de los Jefes de Estado y Gobierno de los Estados Unidos y Canadá) se realizó en septiembre de 1991 en Venezuela. La última de esas conferencias (numerada como la décimo segunda) se realizó en el año 2003 en República Dominicana. Para un resumen del contenido de las mismas puede consultarse: Yanira Kuper Herrera, "Las Conferencias de Primeras Damas, Esposas y Representantes de Jefes de Estado y de Gobierno de las Américas, en el marco de las relaciones interamericanas", mimeografiado, Trabajo de Curso, Maestría de Relaciones Internacionales, Instituto Superior de Relaciones Internacionales, La Habana, 2003.
} 
nuestros pueblos (incluidos nuestras naciones originarias, y los afro latinoamericanos y caribeños, así como nuestras mujeres) pueden y deben plantearse la posibilidad de edificar un futuro diferente al que conducen las tendencias del presente; ya que -como bien ha planteado Francisco José Mojica- esas tendencias (sociales, económicas, políticas, etc.) existen porque han sido el fruto de las estrategias desplegadas por ciertos "actores sociales". Y si las rupturas a esas tendencias no han logrado hacerlas cambiar su rumbo, ha sido porque el poder de otros "actores sociales no ha sido suficientemente fuerte para aniquilarlas". ${ }^{58}$

Por consiguiente, la modificación de las tendencias actuales exige, en primer lugar, la adopción de una actitud proactiva que posibilite la paulatina elaboración y edificación de los escenarios deseados, así como el despliegue en función de ellos de nuevas estrategias y planes de acción dirigidos a comprender y transformar la realidad. Ello implica acumular y organizar las fuerzas que permitan desafiar el sistema de dominación existente y, en especial, su "núcleo duro": el poder político, económico, militar e ideológico-cultural de los "actores sociales" internos y externos actualmente dominantes. Y ello sólo se logrará mediante las multiformes y sistemáticas luchas de los que Xavier Gorostiaga genéricamente denominó "los excluidos". 59

En esas luchas, los intelectuales orgánicos a las causas populares tenemos el deber de elaborar nuevas anticipaciones del futuro o, si se prefiere, nuevas utopías que -como bien las definió Franz Hinkellamert (Hinkellamert, 2003) - nos permitan la crítica constante del presente a partir de las perennes "esperanzas en un futuro mejor" al que pretenden construir las clases dominantes en América Latina y el Caribe y los grupos de poder preponderantes en la potencia imperial que el Libertador Simón 
Bolívar preanunció que parecía destinada por la Providencia "para plagar la América de miserias en nombre de la Libertad" (Bolívar, 1947). Mucho más porque, como dijo José Martí: "Estos no son tiempos para acostarse con el pañuelo en la cabeza, sino con las armas de almohada (...); las armas del juicio, que vencen a las otras. Trincheras de ideas valen más que trincheras de piedra" (Martí, 1975).

\section{Referencias}

BANDEIRA, Luiz Alberto Moniz. Brasil, Estados Unidos y los procesos de integración regional. Nueva Sociedad, Caracas, n. 186, p.142-157, julio-agosto. 2003.

BARBIERI, Eleonora Masini. La futurología en acción. In: Claves del Siglo XXI. París: UNESCO, 2000. p. 41-42.

BENJAMÍN, César y RIBEIRO, Rómulo Tavares. El ALCA, el libre comercio y el futuro de América del Sur. América Latina en Movimiento, Quito, n. 384, p. 2632, mayo 26. 2004.

BERMÚDEZ TORRES, Lilia. Los retos del hemisferio en el ámbito de la seguridad. In: GRABENDORFF, Wolf (ed.). La seguridad regional en las Américas. Bogotá: FESCOL/ Fondo Editorial CEREC, 2003. p. 81-112.

BIZZOZERO, Lincoln. Los cambios de gobiernos en Argentina y Brasil y la conformación de una agenda del MERCOSUR. Nueva Sociedad, Caracas, n. 186, p.128-142, julio-agosto. 2003.

BOLÍVAR, Simón. Carta al coronel Patricio Campbell, Encargadote Negocios de S.M.B, Guayaquil 5 de agosto de 1829. In: Simón Bolívar: Obras Completas. La Habana: Editorial LEX, 1947. Tomo I, p. 736.

CALLONI, Stella y DUCROT, Víctor Ego. Recolonización o Independencia: América Latina en el siglo XXI. Buenos Aires: Grupo Editorial Norma, 2004.

CAPUTO, Dante y otros. La democracia en América Latina: Hacia una democracia de ciudadanos y ciudadanos. Buenos Aires: Aguilar, Altea, Alfaguara, 2004. 
CARDONA C., Diego. Las relaciones Unión Europea-Comunidad Andina: tareas inmediatas. Nueva Sociedad, Caracas, n. 190, p.117-124, marzo-abril. 2004.

CASALS LLANO, Jorge. El MERCOSUR: ¿Precursor de una verdadera integración latinoamericana? Política Internacional, La Habana, n.2, p. 41-57, julio-diciembre. 2003.

CEPAL. El regionalismo abierto en América Latina y el Caribe: La integración económica al servicio de la transformación productiva con equidad. Santiago de Chile, 1994.

COLUMBRES, Adolfo. La emergencia civilizatoria de Nuestra América. La Habana: Centro de Investigación y Desarrollo de la Cultura Cubana "Juan Marinello", 2001.

CORIAT, Benjamín. Globalización de la economía y dimensiones macroeconómicas de la competitividad. Realidad Económica, Argentina, n. 124 y 125.1994.

CORNIL, Fernando. ¿Globalización liberal o imperialismo global? Cinco piezas de un rompecabezas. Temas, Ciudad de La Habana, n. 33-34, p. 14-27. abrilseptiembre. 2003.

DE LA OSSA, Álvaro. Integración y cooperación entre gobiernos centroamericanos. Nueva Sociedad, Caracas, n. 186, p. 60-68, julio-agosto. 2003.

Escogidas en Doce Tomos. Moscú: Editorial Progreso, 1976. Tomo V, p. 372-500.

ESTAY, Jaime. La globalización y sus significados. In: CALVA, José Luis (coord.). Globalización y Bloques Económicos: realidades y mitos. Mexicali, México: Juan Pablos Editor, 1995.

FAYA, Ana Julia. La modernización de la OEA: hacia nuevos mecanismos de seguridad hemisférica. Cuadernos de Nuestra América, n. 21, enero-junio. 1994.

GARCÍA CANCLINI, Néstor. Culturas en la globalización. Caracas: Nueva Sociedad, 1996.

GARCÍA LORENZO, Tania. Economía e integración. Tricontinental, La Habana, n. 159, p. 15-20. 2004.

GARCÍA RIVERA, Gisela. Cuestiones claves del tribunal internacional permanente en materia penal. El tema del tribunal en la agenda de las relaciones EE.UU.-Caribe. Trabajo de Curso de la Maestría de Relaciones Internacionales (mimeografiado), ISRI, 2003. 
GIACALONE, Rita. Integración Norte/Sur y el tratamiento especial y diferenciado en el contexto regional. Nueva Sociedad, Caracas, n. 186, p. 69-85, julio-agosto. 2003.

GOROSTIAGA, Xavier. Hacia una prospectiva participativa. Esquema metodológico. In: LÓPEZ SEGRERA, Francisco y FILMUS, Daniel (coord.). América Latina 2020: Escenarios, alternativas, estrategias. Buenos Aires: Grupo Editorial SRI, 2000.

HAUGHTON-CÁRDENAS, Antonnette. El Caribe hoy. Tricontinental, La Habana, n. 159 , p. 4-8. 2004.

HERZ, Mónica. Límites y posibilidades de la OEA en la esfera de la seguridad. In: GRABENDORFF, Wolf (ed.). La seguridad regional en las Américas. Bogotá: FESCOL/ Fondo Editorial CEREC, 2003. p. 133-154.

HINKELLAMERT, Franz. El cautiverio de la utopía. Pasos, San José, Costa Rica, n. 50, noviembre-diciembre. 2003.

LENIN, Vladimir Ilich. El imperialismo, fase superior del capitalismo. In: Lenin: Obras

MAGARIÑOS, Gustavo. Integración Multinacional: Teoría y Sistemas. Uruguay: ALADI/ ORT, 2000.

MARGOLIS, Mac. Bajo presión: Los ataques políticos a Lula demuestran que no puede complacer a todos. Newsweek en Español, vol. 9, n. 19, 24 de mayo. 2004.

MARTÍ, José. Nuestra América. In: Nuestra América. La Habana: Casa de las Américas, 1975, p. 21.

MARX, Carlos. El capital. La Habana: Editorial Nacional de Cuba, 1962.

MOJICA, Francisco José. Determinismo y construcción del futuro. In: LÓPEZ SEGRERA, Francisco y FILMUS, Daniel (coord.). América Latina 2020: Escenarios, alternativas, estrategias. Buenos Aires: Grupo Editorial SRI, 2000.

MONTOYA, Roberto. El imperio global. Madrid: La esfera de los libros, 2003.

NYE Jr., Joseph. Política de Seguridad de Estados Unidos: retos para el siglo XXI. In: Agenda de la Política Exterior de los Estados Unidos de América. Washington: 
USIS, 1998.

OHMAE, Kenichi. El poder de la Tríada. México: McGraw-Hill, 1991.

PETRAS, James. La geopolítica del Plan Colombia. KOE'YU Latinoamericano, Caracas, n. 82, p. 3-11, abril-junio. 2001.

PIZARRO LEONGÓMEZ, Eduardo. Colombia. El proyecto de seguridad democrática de Álvaro Uribe. Nueva Sociedad, Caracas, n. 186, p. 4-17, julio-agosto. 2003.

RAMÍREZ LÓPEZ, Bereneci. Perspectivas de la integración comercial de Centroamérica. UNAM: Instituto de Investigaciones Económicas, 2002.

REGUEIRO, Lourdes. Integración latinoamericana: Apuntes para un debate. Cuadernos de Nuestra América, La Habana, n. 22, julio-diciembre. 1994.

RUÍZ BLANCO, Miguel Camilo. Visiones de seguridad en las Américas. In: GRABENDORFF, Wolf (ed.). La seguridad regional en las Américas. Bogotá: FESCOL/ Fondo Editorial CEREC, 2003. p. 113-132.

SANTOS, Theotónio dos. La teoría de la dependencia: Balance y perspectivas. España y México: Plaza \& Janés Editores, 2002.

SAXE-FERNÁNDEZ, Jonh. Mexamérica o la dialéctica entre la macro y la microregionalización. Nueva Sociedad, Caracas, n. 143, mayo-junio. 1996.

SERBIN, Andrés. Desafíos y obstáculos políticos del ALCA. Nueva Sociedad, Caracas, n. 186, p. 86-100, julio-agosto. 2003.

STIGLITZ, Joseph E. El malestar en la globalización. Buenos Aires: Editorial Taurus, 2002.

SUÁREZ SALAZAR, Luis. América Latina y el Caribe: Una mirada al pasado desde el futuro. Conferencia pronunciada en el Foro de las Américas, Berlín, República Federal Alemania, 6 de julio del 2004.

SUÁREZ SALAZAR, Luis. El siglo XXI: Posibilidades y desafíos para la Revolución cubana. ed. Cit

SUÁREZ SALAZAR, Luis. La globalización: ¿Fase superior y última del imperialismo? La Habana: Asociación para la Unidad de Nuestra América, 1999. 
SUÁREZ SALAZAR, Luis. La globalización: ¿Última fase de la última fase? Temas, Ciudad de La Habana, n. 33-34, p. 139-148, abril-septiembre. 2003.

SUNKEL, Osvaldo. El desarrollo desde dentro. México: Fondo de Cultura Económica, 1991.

TOURRAINE, Alain. Le retour de l'acteur. Paris, 1984.

VALDÉS, Nelson Roque. La guerra de Iraq y las relaciones transatlánticas. Política Internacional, La Habana, n. 2, p. 58-75, julio-diciembre. 2003.

WALLERSTEIN, Immanuel. Las debilidades de los Estados Unidos y la lucha por la hegemonía. Temas, Ciudad de La Habana, n. 33-34, p. 99-102, abril-septiembre. 2003.

Recebido: 26/02/2005

Aceite final: 30/03/2005 


\section{Resumo}

A partir de los principales enunciados teórico-prácticos de la denominada "prospectiva crítica", luego de tomar posición frente a las discusiones que se están desarrollando en la actualidad en torno a las implicaciones de "la globalización" y del "fenómeno imperialista", así como de realizar una síntesis de los diferentes componentes de lo que su autor ha venido denominando "un nuevo orden panamericano", el artículo realiza un análisis crítico del estado actual de los diferentes proyectos de integración multinacional que se están desarrollando en América Latina y el Caribe: el Sistema de Integración Centroamericano (SICA), la Comunidad del Caribe (CARICOM), la Comunidad Andina de Naciones (CAN) y el Mercado Común del Sur (MERCOSUR).

A partir de ese análisis -y tomando en cuenta algunos de los enunciados de la Iniciativa Bolivariana para las Américas (ALBA), recientemente dados a conocer por los presidentes de la República Bolivariana de Venezuela, Hugo Chávez y Fidel Castro, respectivamente- el autor propone algunas ideas vinculadas a lo que denomina "un nuevo paradigma para la integración multinacional de América Latina y el Caribe" que, al unísono, sea capaz de confrontar la "integración coercitiva" que (a través del ALCA y de los TLC) está impulsando el gobierno de los Estados Unidos en consuno con algunos gobiernos del hemisferio occidental, así como de superar los limitados resultados del "regionalismo abierto" impulsado, desde hace una década, por la Comisión Económica para América Latina (CEPAL).

Palabras-clave: globalización, imperialismo, nuevo orden panamericano, ALCA e integración multinacional de América Latina y el Caribe. 


\section{Latin American and Caribbean multinational integration: an approach from the critical and participatory perspective}

\section{Luis Suárez Salazar}

Based on the main theoretical-practical enunciations of the so-called "critical perspective", after taking stances in face of debates now under way about the implications of "globalization" and the "imperialist phenomenon", as well as conducting a synthesis of the distinct components of what its author has been calling "a new Pan-American order", this article carries out a critical analysis of the distinct projects of multinational integration under development in Latin America and the Caribbean: the System of Central American Integration (SICA), the Caribbean Community (CARICOM), the Andean Community (CAN) y el Common Market of the south (MERCOSUR).

Based on that analysis - and taking into account some of the enunciations of the Bolivarian Initiative for the Americas and the Caribbean (ALBA), recently made public by the presidents of the Bolivarian Republic of Venezuela, Hugo Chávez, and Fidel Castro, respectively - the author proposes some ideas linked to what he calls "a new paradigm for multinational integration in Latin America and the Caribbean", which, in unison, would be able to confront the "coercive integration" encouraged by the US government (through the FTAA and the other FTAs) with other Western governments, as well as to overcome the limited results of "open regionalism" encouraged since a decade ago by the Economic commission for Latin America and the Caribbean (CEPAL).

Key words: Globalization, Imperialism, New Pan-American Order, FTAA, Multinational Integration of Latin America and the Caribbean 